\title{
Evaluation of management and human resource challenges in the establishment of telemedicine in bandar abbas social security hospital, 2017
}

\author{
Mahnaz Khanehfarda ${ }^{1}$, Abbas Ghavam ${ }^{2, *}$, Somayeh Hessam ${ }^{3}$ \\ ${ }^{1}$ PG Student, Dept. of Healthcare Management, Marvdasht Branch, Islamic Azad University, Marvdasht, Iran, ${ }^{2}$ Assistant \\ Professor, Department of Environmental Science, Institute of Sciences and High Technology and Environmental Sciences, \\ Graduate University of Advanced Technology, Kerman, Iran, ${ }^{3}$ Assistant Professor, Department of Health Services \\ Administration, South Tehran branch, Islamic Azad University, Tehran, Iran
}

*Corresponding Author:

Email: ghavam39@gmail.com

\begin{abstract}
Objective: The emergence of internet and its development has made a lot of changes in every science and industry, medical science is not an exception, and the internet, in addition to the effects it has made on its own development, has also had significant effects on the development and improvement of medical services.

Research method: This research is descriptive-qualitative with a phenomenological approach, which has been carried out in 2017 at Bandar Abbas Social Security Hospital (Persian Gulf). The information has been collected through a semi-structured interview with nine hospital staff.

Results: The maxqud10 software was used to encode the collected data. As a result, 76 codes have been extracted out of two main components of management and human resource factors affecting on the establishment of telemedicine, which have been grouped into eight main categories.

Discussion and conclusion: The results of this research can be used to identify managerial and human resource barriers in organizational planning for healthcare organizations.
\end{abstract}

Keywords: Remote treatment, Telemedicine, Challenges of telemedicine establishment, Remote medicine.

\section{Introduction}

The advent of the internet and its development has made a lot of changes in every science and industry, medical science is not an exception too, and the internet, in addition to the effects it has made on its own development, has also had a profound effect on the development and improvement of medical services. ${ }^{1}$ Since telemedicine is used in patient-doctor relationships, technology plays a very important role in creating this relationship. Telemedicine technology issues can be divided into telecommunications, technology for video, sound and network. The first and hardest step for telemedicine programmers is the selection of telecommunication type that includes various types of bandwidth and a variety of telecommunication technologies such as microwave satellite, wireless, cable, and internet. It is beneficial to use it in Iran due to geographical conditions, the existence of impassable mountainous and desert regions, deprived areas with limited medical facilities, the concentration of health and medical facilities in metropolitan areas, the high costs of patient's transfer to healthcare facilities and can fulfill Iranian health needs in deprived areas. ${ }^{2}$ The qualitative study of Grindley et al. indicated a decrease in the number of physician and patient's travel, as well as more temporal and spatial access compared to on-site visits. ${ }^{3}$ The qualitative study of Hiratsukau.et.al also found that telemedicine complements the relationship between the patient and the physician. ${ }^{4}$ Although telemedicine systems have many benefits, such as the distribution of high-quality medical services to remote areas, the failure to comply with the underlying conditions leads to low efficiency and quality of the services they provide, the followings are among the challenges:

1. High technical costs, including high cost of equipment, high cost of preparing telecommunication infrastructure for this purpose, and high costs of the information exchange.

2. Legal constraints and legal arguments that include internal permissions, medical credentials, liability for negligence in treatment, and controversies related to compensation and reimbursement.

3. Cultural factors that include physicians' resistance, resistance of health care providers, and patient resistance. $^{5}$

Today, telecommunication \& information technology is widely used in medicine and its related sciences. Every day, doctors consult each other on their patients with their cell phone. Specialists train specialized points to general practitioners or students through video conferencing systems or internet sites. Physicians store the information of patients' records on personal computers and review them if necessary or send them to a physician. In hospitals, central information systems, vital signs monitoring system and medical paging systems are being commonly used. ${ }^{6}$

It seems that the use of telemedicine in countries such as Iran, due to geographical conditions, the existence of impassable mountainous and desert areas, poor transportation networks, population dispersion, deprived areas with limited medical facilities, the 
concentration of health and medical facilities in metropolitan areas, and the high cost of transferring patients to these areas can help quickly diagnose a disease, adopt proper medical tactics, reduce time waste, reduce diagnostic costs, and make the relationship between specialized hospitals in different cities. However, remote counseling and diagnosis are still unknown and despite many benefits, they have many challenges, the barriers that stop some of the telemedicine projects. Telemedicine is a new approach in providing diagnostic, therapeutic and health care services that is supported by electronic and communication processes. Telemedicine may be a suitable alternative to some common forms of health care services, but there are important barriers to the proper use of this technology. ${ }^{7}$

The findings of the research show that the majority of specialists, lack of technical staff, initial costs, lack of medical personnel and insurance problems and reimbursement are the main obstacles to the establishment and application of this system in hospitals, the order of the services used in telemedicine from the specialists' point of view, is as follows: providing training, counseling, purchasing equipment, providing care, referring patients. ${ }^{2}$

In her article, Elaheh Rashedi, quoted from Ekeland.et al that they have evaluated all of the telemedicine implementations that had taken place until 2010 and measured their effectiveness. The results of this review indicated that:

$64 \%$ of implementations indicated that telemedicine in chronic diseases can be well implemented and has positive effects. These effects increase the impact of treatment, the efficiency of providing health services and the usability of the service. $36 \%$ of implementations also indicated that the effectiveness of telemedicine in some diseases is limited. ${ }^{8}$

If senior managers do not look at this technology as a tool for earning money, it will help treat patients with a better understanding of the health needs of the area and its implementation in the appropriate infrastructure and training of specialized human resource. Many medical trips to other provinces will be reduced in order to receive the same treatment, and will result in patients' satisfaction.

\section{Materials and Methods}

This research is descriptive-qualitative with a phenomenological approach that was carried out at the Social Security Hospital (Persian Gulf) in 2017. Having used interviews with open and semi-structured questions, 9 people from hospital staff were interviewed purposefully. The maxqda10 software was used for open and axial coding. Totally, 76 codes were obtained in eight main categories out of the two main components of managerial and human resource factors. The only tool used to collect information was digital voice recorder.

\section{Results}

This interview was carried out with 9 staff including three physicians, two general practitioners, one MSc in health service Management, one BS in nursing, one computer engineer and one medical document expert. Following table shows what was done after open and axial coding.

Table 1: managerial factors affecting establishment of telemedicine

\begin{tabular}{|c|l|l|l|}
\hline S. N & $\begin{array}{l}\text { Main } \\
\text { component }\end{array}$ & Main category & Subcategories \\
\hline 1. & $\begin{array}{l}\text { Managerial } \\
\text { factors }\end{array}$ & $\begin{array}{l}\text { Support of senior } \\
\text { manager }\end{array}$ & $\begin{array}{l}\text { Providing required } \\
\text { resources }\end{array}$ \\
\cline { 3 - 4 } & $\begin{array}{l}\text { Organizational } \\
\text { issues }\end{array}$ & $\begin{array}{l}\text { Codification and } \\
\text { correction of processes }\end{array}$ \\
\cline { 3 - 4 } & $\begin{array}{l}\text { Lack of certain } \\
\text { instructions from the } \\
\text { organization }\end{array}$ \\
\cline { 3 - 4 } & $\begin{array}{l}\text { Organizational } \\
\text { culture }\end{array}$ & $\begin{array}{l}\text { Resistance against } \\
\text { technology }\end{array}$ \\
\cline { 3 - 4 } & Legal issues & $\begin{array}{l}\text { Lack of legal methods to } \\
\text { pursue medical errors }\end{array}$ \\
\hline
\end{tabular}

\section{Managerial factors}

Managerial factors are a main component abstracted in this research. This component includes categories: senior manager's support, organizational issues, organizational culture, and legal issues.

\section{The support of senior manager}

From views of participants, senior management has an important supporting role by providing the necessary infrastructure, such as the allocation of appropriate internet lines, or the allocation of financial sources and other necessary infrastructures for the implementation of telemedicine. 
"In fact, the senior manager should be able to provide it with a lot of supports from both the financial and other sources, and the facilities that we must have here to do the operation well. In my opinion, if it is supported, the hospital will be very good and it can actually exchange information with large hospitals "participant No. 7 said.

\section{Organizational issues}

One of the most basic challenges of remote treatment establishment is the organizational issues such as lack of specific guidelines from the central social security organization for the establishment of telemedicine. Because without the permission of the central organization, implementation of the project will not be possible. After that, it can be possible to correct and codify the existing processes for the establishment of this technology.

"In our hospital, the Persian Gulf, some effective factors that can play a role, are its managerial factors meaning that we now have this tool and we want to implement it. The organization is the most important. Everywhere, we engage organizational problems. For example, if the head of our hospital was to take action in this regard, the first thing would be organizational permission "participant No. 1 said.

\section{Organizational culture}

Among the issues expressed by the participants was resistance to changes. Especially in remote treatment that requires technology learning, while some people have not learnt new technologies. By expressing the positive features and privileges of telemedicine, senior managers are encouraged to implement it.

"There is resistance to any change. Telemedicine may also be present in some of our colleagues, especially those who less engage themselves in modern technology. Also, some physicians with more work experiences who are not very up-to-date but welcome it"

\section{Legal issues}

What is important from the point of view of participants in the interview in terms of legal issues related to the establishment of telemedicine is the ability to refer to information in this regard in the judicial field. Some problems will be created due to the lack of legal procedures for tracking medical errors.

"It is difficult to establish it because it cannot be referred to legally" participant No. 8 said:

Table 2: human factors affecting establishment of telemedicine

\begin{tabular}{|c|c|c|}
\hline $\begin{array}{c}\text { Main } \\
\text { component }\end{array}$ & Main category & Subcategories \\
\hline \multirow[t]{7}{*}{$\begin{array}{l}\text { Human } \\
\text { factors }\end{array}$} & \multirow[t]{3}{*}{ Educational issues } & $\begin{array}{l}\text { Lack of knowledge on } \\
\text { using telemedicine }\end{array}$ \\
\hline & & $\begin{array}{ll}\begin{array}{l}\text { Empowerment } \\
\text { personnel }\end{array} & \text { of }\end{array}$ \\
\hline & & $\begin{array}{l}\text { Changing the attitude of } \\
\text { senior managers }\end{array}$ \\
\hline & $\begin{array}{l}\text { Cultural context of } \\
\text { the society }\end{array}$ & $\begin{array}{l}\text { The trust rate of patient in } \\
\text { efficiency of telemedicine } \\
\text { system }\end{array}$ \\
\hline & \multirow[t]{2}{*}{ Human resource } & Motivational issues \\
\hline & & Lack of human resource \\
\hline & $\begin{array}{l}\text { Applied medical } \\
\text { issues }\end{array}$ & $\begin{array}{l}\text { Using face-to-face and } \\
\text { traditional methods }\end{array}$ \\
\hline
\end{tabular}

\section{Human factors}

Human factors are the second main component abstracted in this research. This component includes following categories: educational issues, cultural context of the community, human resources and applied medical issues.

\section{Educational issues}

Given the fact that remote treatment is a new phenomenon in medical science, the issue of education is crucial for accepting this knowledge from the participant's point of view. It is possible that the physicians may feel at risk because they are not familiar with it and consider it as their successor because of their inadequate knowledge. It can be solved by training.

"We do not want to replace it with doctors. If Doctors know that nobody wants to replace it with them, certainly they will not resist against it. They resist against it because they do not know it well", the participant No.1 said.

"System managers are fully aware of telemedicine. I think that there is no awareness at the manager level yet. Or no awareness has been given to them about the benefits the telemedicine can have for the hospital and patients. If these so-called system benefits are explained to all managers in a seminar, they will understand that this system can really be helpful in all aspects, in terms 
of exchanging information between doctor and patient", the participant No.2 said.

"It's 100 percent necessary for doctor, nurse, be trained in this regard. However, this is a separate field and cannot be presented with this knowledge and this level of education with the best quality and quantity. Certainly, you need to get the necessary training. It is possible with the present staff but it is necessary for the staff to be trained and reinforced. That is, the specialist who work in these areas and doctors or specialists from other fields train the staff and thus the system will be completely established" the participant No.5 said.

\section{Cultural context of the community}

One of the challenges facing this technology is to prepare the community for accepting this method of treatment. Participants believed that at first, patients should be assured of the efficiency of this type of treatment and then it should be initiated.

"Some resistances are cultural, those that can be created by people, they may not trust in such treatment. It takes time to provide the context and change the culture in order that it is accepted by people" the participant No.4 said.

The participant No. 8 on the relationship between the establishment of remote therapy and its cultural context told that the cultural context of society was the biggest challenge.

\section{Human resources}

Regarding the human resources, paying attention to the lack of specialized human resources and making people motivated can delay the implementation of this technology.

"Regarding lack of human resources in healthcare, in the Social Security Hospital, or generally in our country, the number of doctors is not large to respond the population issue " the participant No.4 said.

"Regarding motivational issues, some points (rewards) should be considered for them to encourage to it " the participant No.1 said.

\section{Applied medical issues}

In this regard, participants believe that many diseases cannot be treated with this method, and patients should be treated in the same way as in the traditional and face-to-face methods.

"But we should remember that the most important thing is in fact face-to-face treatment rather than telemedicine. it is very important for us" the participant No.9 said.

"It is practical in some aspects but it is not practical in many surgical issues because the surgeon must visit his patient. It is not practical to trust in sonography or laboratory. The surgeon may have a wrong diagnosis. Therefore, we have to visit the patient. It may be practical in medical issues such as infants rather surgical ones" the participant No.3 said.
"Sometimes, the patient has to be hospitalized and cared for. Therefore, we cannot use telemedicine. The patient has to visit his doctor so as to be examined or a procedure must be done on the patient" the participant No.4 said.

\section{Discussion}

The findings of this study are illustrative of the problems of telemedicine establishment in Bandar Abbas Social Security Hospital. The components and subgroups extracted from the text of interviews are the main obstacles to the establishment of telemedicine technology at this health center. Management is one of the factors affecting on the implementation of new phenomena and the lack of leadership support is a serious and effective barrier to its implementation. ${ }^{9}$

From the participants' point of view, senior management plays an important role in providing technical infrastructure or supplying financial sources related to it. Data analysis suggests that managerial factors, such as support for senior executives, organizational issues such as permissions and existence of clear and necessary policies for the implementation of new technologies, the lack of legal rules regarding with or without reference to the digital medical documents produced in telemedicine, the existence of an appropriate organizational culture that reduces the staff's resistance against changes, especially in the field of technology will make it easier. All of these are issues that should be considered as the managerial or organizational barriers that impede the implementation of telemedicine technology.

According to the views of the participants who were the hospital staffs, they all emphasized the role and importance of education, and they believed that the importance of this issue is so much that it changes the view of the managers and attract them on the implementation of this project. Another point is the lack of adequate knowledge of patients about the importance and necessity of using this technology when necessary and using it to control and manage illness.

"It is important to provide a situation that patients can play an active and collaborative role in controlling and managing their illness by using tools." 10

It is important to pay attention to human factors meaning paying attention to the educational issues needed by the organization and the society and providing the cultural context of community for accepting this treatment against traditional treatments that the physician was attending to the patient's bedside.

In this method, patients refuse to express their medical history correctly because they cannot communicate with the physician on the other side of the connection point by only seeing him through the monitor, and such communication has no logical justification for them.

According to the findings of the Hiratsuka et al., if the first interaction was face-to-face and treatment is 
done by the same provider, it would complement the relationship between the doctor and the patient in the telemedicine. ${ }^{4}$ Of the most important applications of telemedicine in remote areas is to provide such services for people in these regions due to lack of access to the physician. This is itself a factor in reducing travel to cities and other provinces to receive health care.

This method improves access and medical care for patients, and even provides better, faster and easier access to counseling for deprived rural areas. ${ }^{11}$

There is also a lack of efficient and expert human resources throughout the country or an incorrect distribution of specialized physicians in a region that will deprive remote and rural areas of proper healthcare services.

"The inappropriate distribution of specialists who work only in cities and rural areas do not have treatment facilities such as maternal-fetal critical care, neurology, and cardiology, and telemedicine can solve this problem." 12

\section{Conclusion}

In line with the establishment of remote treatment, management and human resource factors are two very strong levers. This is not possible without the existence of management factors such as the necessary regulations to provide the necessary infrastructure for the establishment of this technology. A major challenge in this regard is the lack of legal rules in complaints and pursuits. Prior to starting this program, cultural issues should be addressed and the social context should be prepared in order to accept this treatment.

\section{References}

1. Amirani, Hossein 2015, "The Principles of Telemedicine ", informational educational-research quarterly of Noandish Sabz., ninth year. No. thirty four and thirty five. Summer and fall 2015.

2. Rahimzadeh, E. et.al, 2012 "Feasibility study on the use and establishment of telemedicine in Imam Khomeini Hospital", Ardebil, Kadouseh scientific-student quarterly, period 2, No. 2, Summer 2012.

3. GRINDLAY, K., LANE, K. \& GROSSMAN, D. 2013. Women's and providers' experiences with medical abortion provided through telemedicine: a qualitative study. Women's Health Issues, 23, e117-e122

4. HIRATSUKA, V., DELAFIELD, R., STARKS, H., AMBROSE, A. J. \& MAU, M. M. 2013. Patient and provider perspectives on using telemedicine for chronic disease management among Native Hawaiian and Alaska Native people. International journal of circumpolar health, 72.

5. Parsaei, MR et al. 2016 "Presentation of a new method for improving network monitoring in telemedicine applications using software-based networks". The first international conference on the new research achievements in electrical and electronic engineering, 2016.

6. Moeini, Ebrahim-Bakhtiari Zohreh 2010 "Identifying and Investigating Effective Factors in the Application of Telemedicine Technology in Iranian Hospitals" The
Fourth National Conference on Technology Management of Iran 2010.

7. Ehsani, Saffura-Zargar Seyyed Mohammad 2015 «Identification and prioritization of barriers to the use of telemedicine technology in medical centers (Case study: Shahid Beheshti University of Medical Sciences) The first congress of applied research in Industrial Management of Azad University of Semnan, 2015.

8. Rashedi, E-Barati, Allah, 2013 "Remote technology and its effectiveness" Scientific-research Journal of Pajuhan, period 11, Spring 2013.

9. CECILIE VARSI, MS MIRJAM EKSTEDT, PhD DEEDE GAMMON, PhD ELIN BØRØSUND, MS CORNELIA M. RULAND, PhD "Middle Managers' Experiences and Role in Implementing an Interactive Tailored Patient Assessment eHealth Intervention in Clinical Practice"CIN: Computers, Informatics, Nursing \& Vol. 33, No. 6, 249-57.

10. Nazli Bashi1, , RN, MAppSc; Mohanraj Karunanithi1, PhD; Farhad Fatehi1, , MD, PhD; Hang Ding1, PhD Darren Walters, MD, PhD "Remote Monitoring of Patients With Heart Failure: An Overview of Systematic Reviews"2017 JOURNAL OF MEDICAL INTERNET RESEARCH.

11. Saeedi Tehrani, S-Nowruzi M 2015 "Remote Medicine: A Review of Benefits, Disadvantages and Ethical Challenges" Iranian Journal of Medical Ethics and History, Period. 8, No. 2, July 2015.

12. Curtis L. Lowery, Janet M. Bronstein, Tina L. Benton, and David A. Fletcher "Distributing Medical Expertise: The Evolution And Impact Of Telemedicine In Arkansas"2015- HEALTH AFFAIRS 33, NO. 2 (20 14):235-43. 